\title{
Patterns of axillary bud activity in white clover
}

\author{
P.C.D. NEWTON, M.J.M. HAY', V.J. THOMAS*, E.M. GLASGOW and H.B. DICK \\ MAF Technology, Flock House, Private Bag, Bulls \\ 'DSIR Grasslands and 'Physical Sciences, Private Bag, Palmerston North
}

\begin{abstract}
The activity of white clover axillary buds was studied over a 13 month period in populations from set-stocked (S) and rotationally grazed (R) pastures. Bud activity in the field was observed and the viability of inactive buds was tested in the laboratory. $\mathrm{R}$ populations had significantly greater percentages of nodes bearing active buds, potentially active buds and roots. Two kinds of dormancy were identified in axillary buds. For much of the year buds at approximately $26 \%$ of nodes were prevented from growing, probably by a combination of correlative factors and the environmental conditions surrounding each bud-site. During spring, very few buds could be stimulated to grow; these buds were regarded as showing the second form of dormancy. The $\mathrm{R}$ population had a deeper but less prolonged 'spring dormancy'. The physiological basis and ecological significance of 'spring dormancy' are considered.
\end{abstract}

Keywords white clover, dormancy, axillary b u d s

\section{Introduction}

In permanent pastures regeneration of white clover is almost exclusively vegetative (Chapman 1987). Consequently an understanding of the basis of persistency and productivity of a population must follow and quantify the activity of the 'bank' of vegetative buds. An axillary bud is associated with each stolon node so that the total vegetative 'bud bank' may be estimated-by taking the- total node number in the population and subtracting the numbers of nodes which have previously borne branches or flowers. However, the resulting value does not give an accurate assessment of the number of potential branches as bud viability, dormancy and bud state (i.e. vegetative or reproductive) are ignored. As with seed banks, both viability and dormancy are critical to an understanding of how and why changes in population numbers occur. This paper considers how the activity of clover buds is influenced by season and grazing management.

\section{Materials and methods}

The pastures were sown in 1978 with a mixture of white clover ('Grasslands Huia') and perennial ryegrass ('Grasslands Ruanui'). The grazing managements employed were either continuous setstocking $(\mathrm{S})$ or a rotational system $(\mathrm{R})$. Both managements had the same stocking rate (22.5 ewes + lambs/ha) and the same pasture utilisation $(11,500$ $\mathrm{kg} \mathrm{DM} / \mathrm{ha} / \mathrm{yr}$ ).

Monthly samples of individual plants were taken from the clover populations from June 1988 until June 1989. A steel edged quadrat $(300 \times 300 \mathrm{~mm})$ was used to lift $\mathbf{5 0} \mathrm{mm}$ deep turves, six from the $\mathbf{S}$ and two from the R pastures. Each turf was washed to remove soil and then clover plants were separated intact from the vegetation mat. The plants were classified according to their branching complexity. Third order plants, that is plants with primary, secondary and tertiary stolons (Brock et al. 1988), were selected for this study. This category was taken as representative of the population, as third order plants contain a greater proportion of the growing point population than any other category (Brock $e$ al-1988)-In-the-absence of-suitable third order plants then second order plants were used.

Two plants were taken from each quadrat for incubation to assess the pdtential of buds that were inactive in the field. The positions of nodes with branches and roots were recorded and roots and leaves were removed. The stolons of each plant were then sequentially dissected into individual nodes. The nodes of each plant were placed in order on germination cards on moist towelling containing the fungicide benomyl in plastic incubating trays $(30 \mathrm{x} 20$ x $8 \mathrm{~cm}$ ) and the trays sealed with plastic film. Incubation was at $20^{\circ} \mathrm{C}$ in constant low light (PAR $20 \mu \mathrm{E} / \mathrm{m}^{2} / \mathrm{s}$ ). Preliminary experiments (unpublished) had shown these conditions to be optimal for stimulating bud activity. Between 1500 and 2000 nodes were assessed at each sampling. Bud activity was assessed during an incubation period of 28 days. The following categories were used to describe axillary buds:

1. active bud: a bud from which visible growth (i.e. green leaf) was visible at the time of sampling. 
2. potentially active bud: a bud that showed no visible growth in the field but was stimulated to grow by incubation.

The numbers of buds falling in these categories were then expressed as a percentage of the total nodes sampled.

Root activity was divided into roots that were present in the field and root primordia that were stimulated to grow during incubation. In fact, very few root primordia became active during incubation (4\%), although the conditions had previously been shown to stimulate growth. Consequently, the two categories were combined giving one category which primarily reflected root presence in the field.

The numbers of flowers and reproductive buds were counted but the combined value did not comprise more than $1 \%$ of the total nodes at any sampling. Therefore, bud state (reproductive or vegetative) was not considered an important element in the analysis.

\section{Results}

Over the sampling period the $\mathrm{R}$ population had significantly greater percentages of nodes that bore active buds, potentially active buds and roots (Table 1). The relative differences were respectively $19.6 \%$, $16.2 \%$ and $25.5 \%$.

In the material sampled the percentage of nodes with active buds fell during the spring period and then recovered to a winter peak (Fig. la). A similar pattern was evident for potentially active buds with a particularly marked depression in spring (Fig. lb). The spring decline was most evident in the $\mathrm{R}$ population but the period of inactivity was shorter.

Both populations had a peak of root activity in spring with the $\mathrm{R}$ peak being more marked (Fig. lc). A greater percentage of $\mathrm{R}$ nodes were likely to have roots at any period of the year (Fig. lc).

Table 1 Percentage of nodes bearing active buds, potentially active buds or roots in two clover populations. Values are means (SEM) for a 13 month period.

\begin{tabular}{|c|c|c|}
\hline & Rotational & Set-stocked \\
\hline Active buds & $21.9(1.39)$ & $17.6(0.79)$ \\
\hline Potentially active buds & $30.3(1.42)$ & $25.4(1.05)$ \\
\hline Roots & $47.1 \quad(2.34)$ & $35.1(1.05)$ \\
\hline
\end{tabular}

\section{Discussion}

Two types of dormancy appeared to be present in the white clover axillary buds. During much of the year a proportion of buds remained inactive in the field but could be stimulated to grow by the separation of individual nodes and by incubation in 'ideal' conditions (the 'potentially active' category). The factors controlling bud activity were thus likely to be a combination of correlative factors (e.g. control by the apex) and the nature of the conditions surrounding each bud-site, factors which Romberger
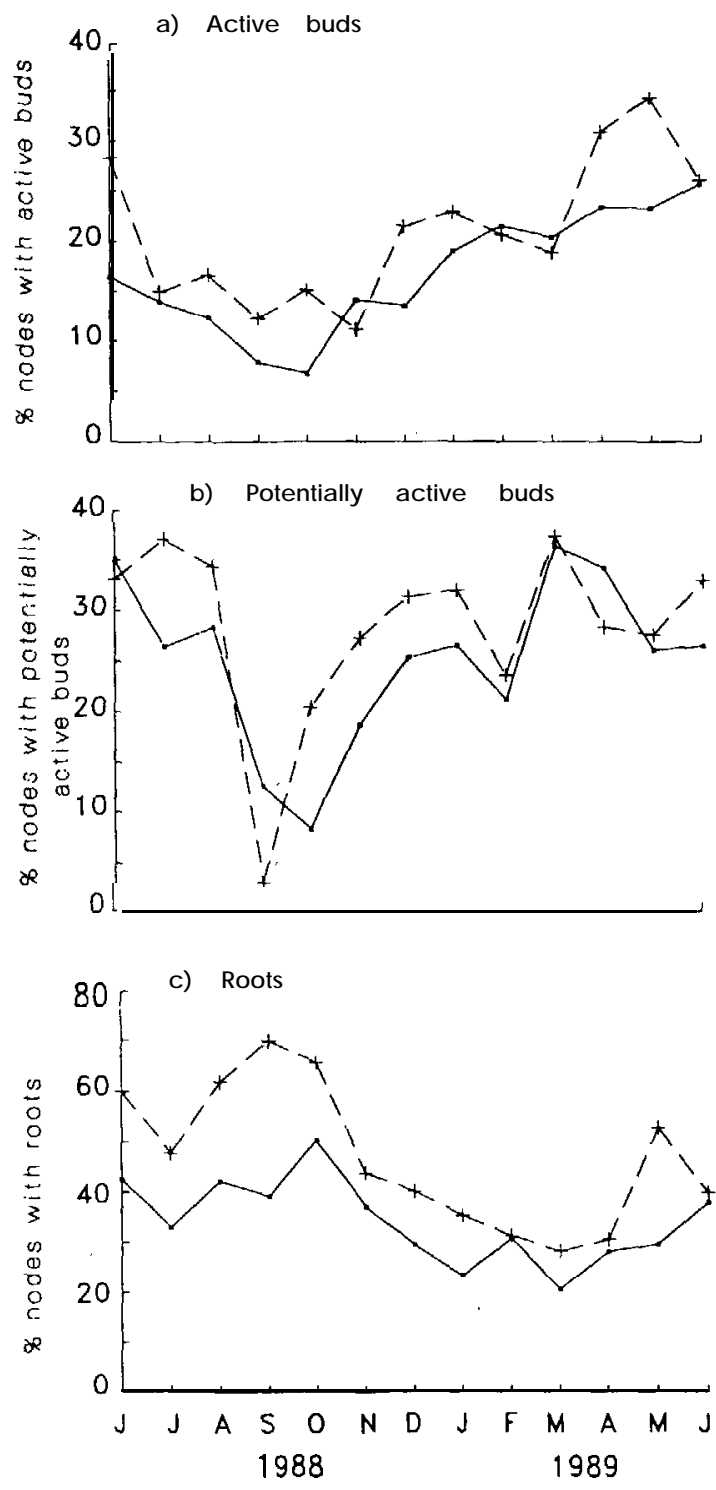

Figure 1 Seasonal changes in the percentage of nodes bearing a) active buds, b) potentially active buds or c) roots in white clover plants sampled from rotationally grazed $(\cdot . \cdot)$ or set-stocked $(-)$ pastures.

(1963) has described as quiescent. The $\mathrm{R}$ population had significantly more buds in this first dormancy category (Table 1).

In a study conducted on infrequently grazed pastures in Wales, Davies \& Dutta (1988) reported that $42.5 \%$ of inactive buds were stimulated into growth by mist propagation. If the number of potentially active buds in our study is calculated as a percentage of the inactive buds, rather than as a percentage of the total node population. the value 
for $\mathrm{R}$ is $42.5 \%$ and for $\mathrm{S}$ is $31.8 \%$. As a generalisation it may thus be said that $3040 \%$ of inactive buds are likely to be viable. In the populations we sampled this viable fraction comprised approximately $26 \%$ of the total node population.

A second kind of dormancy appeared to occur during the spring period. At this time, very few buds could be stimulated to grow (Fig. lb). The lack of activity was evident in buds of all ages (Newton, P.D.C., Hay, M.J.M., Thomas, V.J. unpublished), and this fact, together with the restoration of activity at subsequent samplings, suggests that the capacity for growth was temporarily rather than permanently lost. In other words the response was due to dormancy not mortality. This 'spring dormancy' has not been previously reported in white clover.

Climate data for the August to November period show no noticeable deviations from the long-term averages; thus is seems unlikely that the dormancy was a response to unusual climatic conditions. An appropriate analogy is perhaps with Elymus repens (= Agropyron repens), in which a 'late-spring dormancy' of rhizome buds has been described (Johnson \& Buchholtz 1962; Leakey et al. 1977a). Leakey $\boldsymbol{e t}$ al. (1977a) argue that this dormancy is unlike winter dormancy or the summer dormancy found in some perennial grasses (Laude 1953), and should also be distinguished from a more general pattern of bud suppression that results from correlative inhibition.

The 'late-spring dormancy' of $\boldsymbol{E}$. repens rhizome buds occurs at the period of most rapid shoot and rhizome growth (Leakey et al. 1977a). In the closely related $\boldsymbol{E}$. farctus a similar 'spring dormancy' of rhizome buds also occurs, coinciding with a flush of root and shoot growth (Harris \& Davy 1986). Although application of nitrogen restored bud activity in E. repens (Leakey et al. 1977b), this was not an invariable response and in some circumstances carbohydrate appeared to be limiting (Leakey et al. 1977a).

The factors involved in white clover 'spring dormancy' are not fully understood. However, a number of changes in plant structure and physiology are reported to occur during the spring period. These include fragmentation of plants (Hay et al. 1988) and a sharp decline in starch content of the stolons (Hay et al. 1989). Spring is also the period of maximum root activity (Brock et al. 1988; Fig. 1c). Some of the changes occurring in spring appear to be expressed differently in $\mathrm{R}$ and $\mathrm{S}$ populations, for example changes in plant weight. and branching complexity are more exaggerated in plants in R swards (Hay et al. 1988). In relation to 'spring dormancy', it was observed that the dormancy in $\mathrm{R}$ buds sampled was deeper but less prolonged than in S buds (Fig. lb).

Rapid growth in white clover is characterised by prolific axillary bud activity (Harvey 1979).
Therefore a better definition of the factors limiting axillary bud activity in the field (i.e. an understanding of our first dormancy category) is desirable if yield increases are to be achieved. The second dormancy category, 'spring dormancy', may be added to the list of changes that occur within clover plants during spring; a period which appears to be of particular importance to the survival and growth of clover populations (Hay et of. 1988). Consequently, further analysis of the ecological significance of 'spring dormancy' may contribute to a better definition of management practices that result in stable populations of white clover.

\section{REFERENCES}

Brock, J.L.; Hay, M.J.M.; Thomas, V.J.; Sedcole, J.R. 1988. Morphology of white clover (Trifolium repens L.) plants in pastures under intensive sheep grazing. Journal of agricultural science, Camb. 111: 273-283.

Chapman, D.F. 1987. Natural reseeding in Trifolium repens demography in grazed hill pastures. 2. Seedling appearance and survival. Journal of applied ecology 24: $1037-1043$

Dairies, A.; Dutta, M.J. 1988. Factors influencing the relationship between branching in white clover and tillering in grass in the field. Proceedings British Grassland Society Research Meeting No. I.

Harris, D.; Davy, A.J. 1986. Regenerative potential of Elymus farctus from rhizome fragments and seed. Journal of ecology 74: 1057-1068.

Harvey, H.J. 1979. The regulation of vegetative reproduction. $\mathrm{PhD}$ Thesis, University of Wales.

Hay, M.J.M.; Brock, J.L.; Thomas, V.J.; Knighton, M.V. 1988. Seasonal and sheep grazing management effects on branching structure and dry weight of white clover plants in mixed swards. Proceedings NZ Grassland Association 49: 197-201.

Hay, M.J.M.; Chu, A.C.P.; Knighton, M.V.; Wewala, S. 1989. Variation with season and node position in carbohydrate content of white clover stolons. Proceedings XVI International Grassland ${ }^{-1}$ Congress: 1059-1060.

Johnson, B.C.; Buchholtz, K.P. 1962. The natural dormancy of vegetative buds on the rhizomes of Agropyron repens. Weeds 10: 53-57.

Laude, H.M. 1953. Nature of summer dormancy in perennial grasses. Botanical gazette 114: 284-292.

Leakey, R.R.B.; Chancellor, R.J.; Vince-Prue, D. 1977a. Regeneration from rhizome fragments of Agropyron repens. I. The seasonality of shoot growth and rhizome reserves in single-node fragments. Annals of applied biology 87: 423431.

Leakey, R.R.B., Chancellor, R.J. \& Vince-Prue, D. 1977 b. Regeneration from rhizome fragments of Agropyron repens. II. The breaking of 'late spring dormancy' and the influence of chilling and node position on growth from single-node fragments. Annals of applied biology 87: 433-441.

Romberger, J.A. 1963. Meristems, growth and development in woody plants. USDA Technical Bulletin 1293. 